Provided for non-commercial research and education use. Not for reproduction, distribution or commercial use.

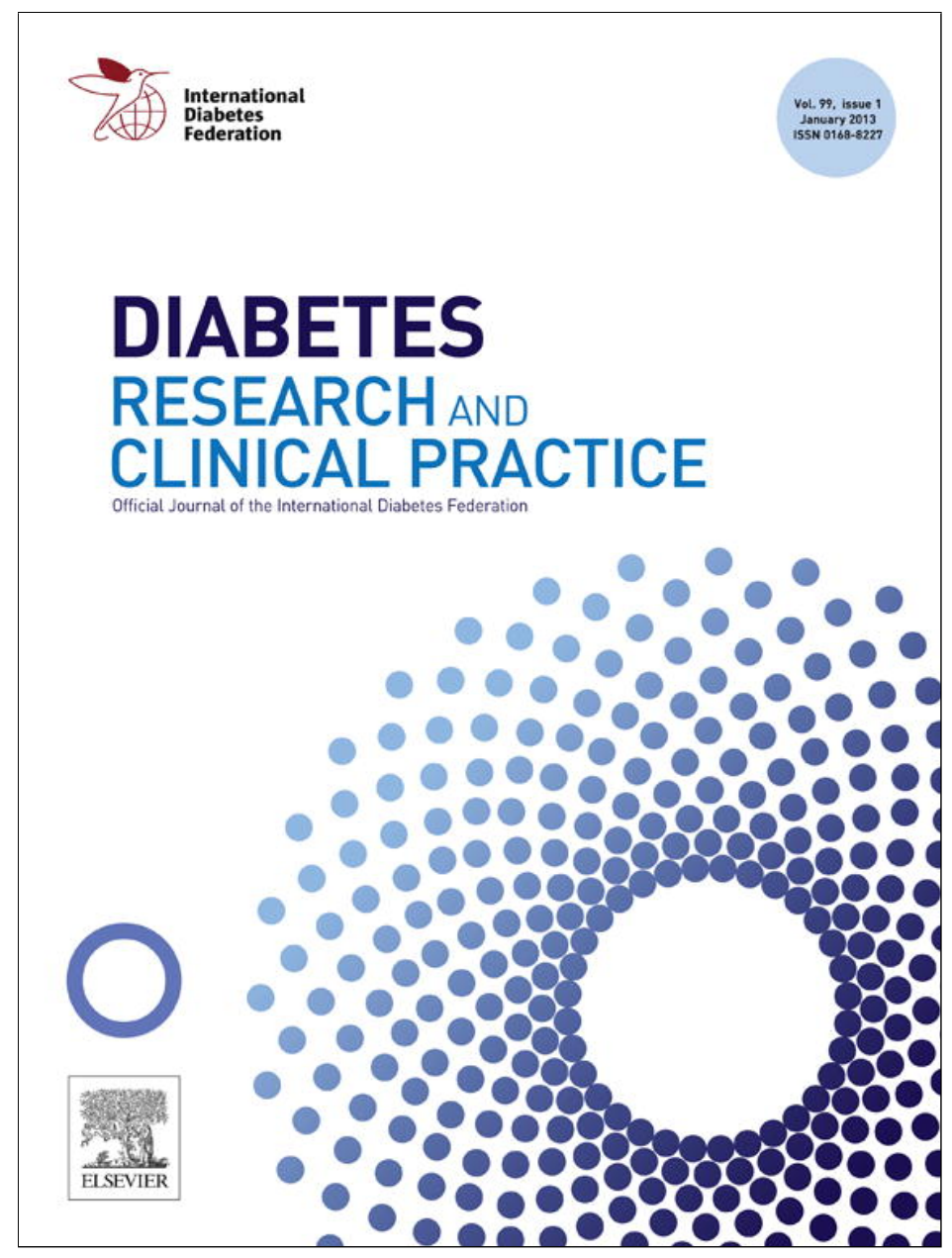

This article appeared in a journal published by Elsevier. The attached copy is furnished to the author for internal non-commercial research and education use, including for instruction at the authors institution and sharing with colleagues.

Other uses, including reproduction and distribution, or selling or licensing copies, or posting to personal, institutional or third party websites are prohibited.

In most cases authors are permitted to post their version of the article (e.g. in Word or Tex form) to their personal website or institutional repository. Authors requiring further information regarding Elsevier's archiving and manuscript policies are encouraged to visit:

http://www.elsevier.com/copyright 


\section{Diabetes Research and Clinical Practice}

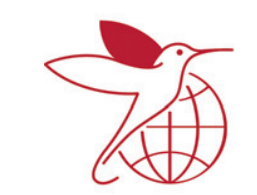

\section{Letter to the Editor}

\section{Seven-day subcutaneous continuous glucose monitoring demonstrates that treatment with acarbose attenuates late dumping syndrome in a woman with gastrectomy for gastric cancer}

\section{Dear Editor,}

Late dumping syndrome is a possible complication of upper gastrointestinal surgery [1]. The symptoms occur one to three hours after eating and include weakness, sweating, dizziness, confusion, and loss of consciousness. These are a result of a sudden increase in blood glucose due to the rapid passage of carbohydrates into the small intestine and subsequent absorption, which causes excessive insulin secretion [2]. Diet with at least 5 meals containing equal amounts of carbohydrates is the treatment of choice, though symptoms may persist and require pharmacologic treatment. It has been reported that $\alpha$-glucosidase inhibitors significantly ameliorate the neuroglycopenic symptoms of late dumping syndrome [3-5]. In such cases, monitoring glycemia with non-invasive subcutaneous continuous glucose monitoring (SCGM) [6] may be useful for the diagnosis and determining appropriate treatment.

We present the case of a 55-year-old woman (weight $56.5 \mathrm{~kg} ;$ BMI $21.8 \mathrm{~kg} / \mathrm{m}^{2}$ ) who underwent gastrectomy for gastric cancer in 2010. Type 2 diabetes was diagnosed in 2006 and she was treated with sulfonylurea which was discontinued after gastrectomy. Following surgery, severe symptoms of blurred vision, diaphoresis, confusion and episodic loss of consciousness occurred one to three hours after eating, and were related to low capillary blood glucose levels. Late dumping syndrome was diagnosed and she was
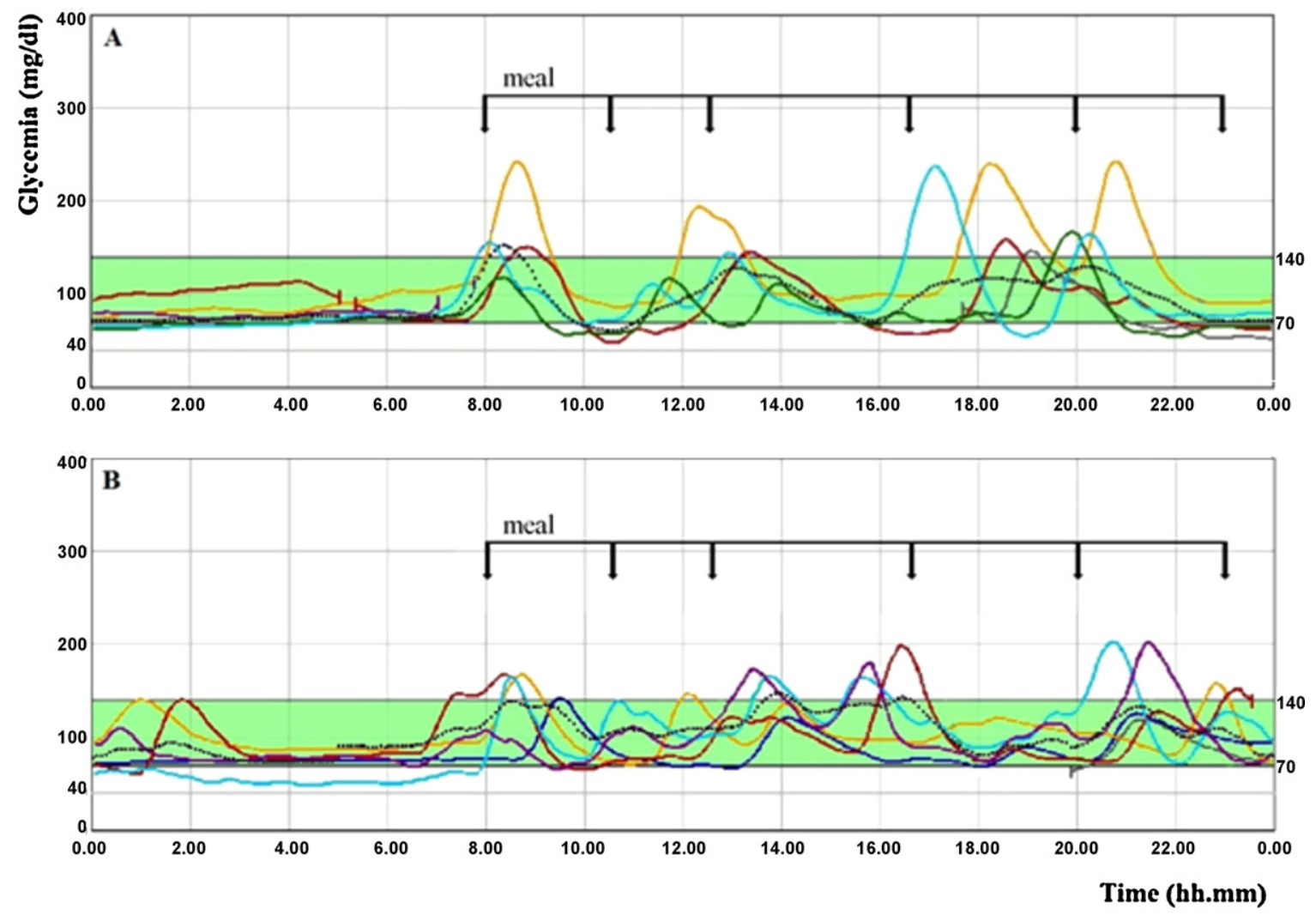

Fig. 1 - Seven-day evolution of glycemia evaluated by subcutaneous continuous glucose monitoring in a gastrectomized woman with late dumping syndrome before $(A)$ and after $(B)$ treatment with acarbose. 
referred to our hospital. Treatment with acarbose $25 \mathrm{mg}$ before breakfast, lunch, and dinner was started. 7-Day SCGM (ENLITE Glucose Sensor; Medtronic Minimed, Northridge, CA, USA) was performed before and soon after treatment with acarbose and average 7-day glycemia, standard deviation, coefficient of variability (CV\%), number of hypoglycemic (glycemia $<70 \mathrm{mg}$ / dl) or hyperglycemic (glycemia $>140 \mathrm{mg} / \mathrm{dl}$ ) events was calculated (Fig. 1) [7]. During therapy with acarbose, there was a significant improvement in symptoms and no episode of loss of consciousness. Before acarbose treatment, average 7day glycemia (mean $\pm \mathrm{SD}$ ) was $91 \pm 37 \mathrm{mg} / \mathrm{dl}$, with $28 \%$ of values in the hypoglycemia range, and $11 \%$ above the hyperglycemic threshold; CV was $40.7 \%$. After acarbose treatment, 7-day glycemia was $99 \pm 34 \mathrm{mg} / \mathrm{dl}$, with $10 \%$ of values in the hypoglycemia range and $17 \%$ above the hyperglycemic threshold; CV was $34.3 \%$. Therefore acarbose reduced the incidence of hypoglycemia, ameliorated the late dumping symptoms but increased the duration of hyperglycemia. A previous report [8] has documented favorable effects of acarbose on late dumping syndrome with CSGM in a patient who had undergone bariatric surgery. Our case report provides further evidence of successful medical treatment of late dumping syndrome with acarbose and highlights the usefulness of SCGM as an investigative tool.

\section{Conflict of interest}

The authors declare that they have no conflict of interest.

\section{RE FERENCES}

[1] Mine S, Sano T, Tsutsumi K, Murakami Y, Ehara K, Saka M, et al. Large-scale investigation into dumping syndrome after gastrectomy for gastric cancer. J Am Coll Surg 2010;211:628-36.

[2] Tack J, Arts J, Caenepeel P, De Wulf D, Bisschops R. Pathophysiology, diagnosis and management of postoperative dumping syndrome. Nat Rev Gastroenterol Hepatol 2009;6:583-90.

[3] Peter S. Acarbose and idiopathic reactive hypoglycemia. Horm Res 2003;60:166-7.
[4] Ozgen AG, Hamulu F, Bayraktar F, Cetínkalp S, Yilmaz C, Túzún $\mathrm{M}$, et al. Long-term treatment with acarbose for the treatment of reactive hypoglycemia. Eat Weight Disord 1998;3:136-40.

[5] Tamura Y, Araki A, Chiba Y, Horiuchi T, Mori S, Hosoi T. Postprandial reactive hypoglycemia in an oldest-old patient effectively treated with low-dose acarbose. Endocr J 2006;53:767-71.

[6] Daniloff GY. Continuous glucose monitoring: long-term implantable sensor approach. Diabetes Technol Ther 1999;1:261-6.

[7] Buscemi S, Re A, Batsis JA, Arnone M, Mattina A, Cerasola G, et al. Glycemic variability using continuous glucose monitoring and endothelial function in the metabolic syndrome and in type 2 diabetes. Diabet Med 2010;27:872-8.

[8] Hanaire H, Dubet A, Chauveau ME, Anduze Y, Fernandes M, Melki V, et al. Usefulness of continuous glucose monitoring for the diagnosis of hypoglycemia after a gastric bypass in a patient previously treated for type 2 diabetes. Obes Surg 2010;20:126-9.

Silvio Buscemi* Alessandro Mattina Gaspare Genova ${ }^{1}$ Pietro Genova ${ }^{1}$ Emilio Nardi

Miriam Costanzo Dipartimento di Medicina Interna e Specialistica (DIMIS) - Laboratorio di Nutrizione Clinica, Italy

*Corresponding author at: Dipartimento di Medicina Interna e Specialistica (DIMIS), Policlinico P. Giaccone, Via del Vespro,

129 - I-90127 Palermo, Italy.

Tel.: +39 91 6554580; fax: +39 916554580

E-mail address: silbus@tin.it (S. Buscemi)

${ }^{1}$ Dipartimento di Discipline Chirurgiche ed Oncologiche, Facoltà di Medicina, University of Palermo, Italy.

19 September 2012

0168-8227/\$ - see front matter (C) 2012 Elsevier Ireland Ltd. All rights reserved. http://dx.doi.org/10.1016/j.diabres.2012.10.021 